\section{JURNAL EKONOMI EFEKTIF}

ISSN : $2622-8882$, E-ISSN : 2622-9935

Jurnal Ekonomi Efektif, Vol. 4, No. 2, Januari 2022 @ Prodi Manajemen Fakultas Ekonomi

Universitas Pamulang

\title{
PENGARUH DEBT TO ASSET RATIO TERHADAP RETURN ON ASSET PADA PT ASURANSI SINAR MAS, TBK PERIODE TAHUN 2011-2020
}

\author{
Molbi Febrio Harsanto ${ }^{1 *}$, Nurjaya ${ }^{2}$, Destiana Kumala ${ }^{3}$, Denok Sunarsi ${ }^{4}$, Heri Erlangga ${ }^{5}$ \\ ${ }^{1,3}$ STEBIS Bina Mandiri, Cileungsi, Bogor, Jawa Barat, Indonesia \\ ${ }^{2}$ Universitas Suryakancana, Cianjur, Jawa Barat, Indonesia \\ ${ }^{4}$ Universitas Pamulang, Tangerang Selatan, Banten, Indonesia \\ ${ }^{5}$ Universitas Pasundan, Bandung, Jawa Barat, Indonesia \\ molbi@binamandiri.ac.id"
}

Manuskrip: Desember-2021; Ditinjau: Desember-2021; Diterima: Desember-2021; Online: Januari -2022;

Diterbitkan: Januari-2022

\begin{abstract}
ABSTRAK
Penelitian ini bertujuan untuk mengetahui pengaruh Debt to Asset Ratio terhadap Return On Asset pada PT. Asuransi Sinar Mas, Tbk Periode Tahun 2011-2020. Metode yang digunakan adalah explanatory research. Teknik analisis menggunakan analisis statistik dengan pengujian regresi, korelasi, determinasi dan uji hipotesis. Hasil penelitian ini variabel Debt to Asset Ratio diperoleh nilai rata-rata sebesar 67,68\%. Variabel Return On Asset diperoleh nilai rata-rata $1,075 \%$. Debt to Asset Ratio berpengaruh positif dan signifikan terhadap Return On Asset dengan nilai persamaan regresi $\mathrm{Y}=17,889-0,190 \mathrm{X}$, dan nilai koefisien korelasi -0,699 atau memiliki tingkat hubungan yang negatif kuat dengan nilai determinasi sebesar $48,8 \%$. Uji hipotesis diperoleh signifikansi $0,025<0,05$.
\end{abstract}

Kata Kunci: Debt to Asset Ratio, Return On Asset

\begin{abstract}
This study aims to determine the effect of Debt to Asset Ratio on Return On Assets at PT. Sinar Mas Insurance, Tbk Period 2011-2020. The method used is explanatory research. The analysis technique uses statistical analysis with regression, correlation, determination and hypothesis testing. The results of this research variable Debt to Asset Ratio obtained an average value of $67.68 \%$. The Return On Assets variable obtained an average value of $1.075 \%$. Debt to Asset Ratio has a positive and significant effect on Return On Assets with a regression equation value of $Y=17.889-0.190 X$, and a correlation coefficient value of -0.699 or has a strong negative relationship with a determination value of $48.8 \%$. Hypothesis testing obtained a significance of $0.025<0.05$.
\end{abstract}

Keywords: Debt to Asset Ratio, Return On Assets 


\section{PENDAHULUAN}

\section{A. Latar Belakang}

Suatu kegiatan usaha dalam bisnis yang dijalankan oleh suatu perusahaan tentulah memiliki beberapa tujuan yang ingin dicapai. Pertama, perusahaan memiliki keuntungan yang optimal atas usaha yang dijalankannya. Mengapa? Karena setiap perusahaan menginginkan modal yang telah ditanamkan dalam usahanya segera cepat kembali. Disamping itu, perusahaan juga mengharapkan adanya hasil atas modal atau investasi baru.

Laba atau keuntungan yang diperoleh merupakan pencapaian target keuntungan yang sangat penting karena dengan pencapaian target yang telah ditetapkan atau bahkan melibihi target yang diinginkan, hal tersebut merupakan prestasi tersendiri bagi pihak manajemen. Prestasi tersebut merupakan ukuran untuk menilai kesuksesan manajemen dalam mengelola perusahaan (baik jenjang karier maupun penghasilan).

Disamping itu, dengan laba ini dapat digunakan perusahaan untuk tambahan pembiayaan dalam menjalakan usahanya dan yang terpenting adalah sebagai alat untuk menjaga kelangsungan hidup perusahaan.

Laba hanya bisa diperoleh dengan adanya kinerja yang baik dari perusahaan itu sendiri. (Kasmir).2012:7) menjelaskan bahwa sudah merupakan kewajiban setiap perusahaan untuk membuat dan melaporkan keuangan perusahaannya pada suatu periode tertentu. Hal yang dilaporkan kemudian dianalisis sehingga dapat diketahui kondisi dan posisi perusahaan terkini. Kemudian laporan keuangan juga akan menentukan langkah apa yang dilakukan perusahaan sekarang dan ke depan, dengan melihat berbagai persoalan yang ada baik kelemahan maupun kekuatan yang dimilikinya.

Agar tujuan dapat dicapai manajemen perusahaan harus mampu membuat perencanaan yang tepat dan akurat. Salah satunya dengan memantau kondisi dan posisi keuangan perusahaan dimana setiap perusahaan harus mampu membuat catatan keuangan selama periode tertentu yang dibuat dalam bentuk laporan keuangan.

Untuk mampu memahami laporan keuangan, perlu dilakukannya analisis laporan keuangan selain dapat menilai kinerja keuangan perusahaan, aspek penting dapat memberikan gambaran mengenai kondisi kesehatan keuangan tersebut, maka pihak manajemen dan para investor dapat mengetahui baik atau tidaknya kondisi kesehatan perusahaan.

Salah satu manfaat analisis laporan keuangan yang tersirat dalam kutipan menurut Horne dan Wachowiz Jr. (2012:154) yaitu "Untuk membuat keputusan yang rasional guna memenuhi tujuan perusahaan, manajer keuangan harus memiliki alat-alat analisis". Selanjutnya dijelaskan bahwa alat-alat analisis yang dimaksud adalah analisis laporan keuangan. Sehingga dapat ditarik kesimpulan bahwa tujuan dan manfaat dari analisis laporan keuangan adalah untuk membuat keputusan yang rasional guna memenuhi tujuan perusahaan.

Penggunaan informasi keuangan yang disediakan sebuah perusahaan biasanya analis atau investor akan menghitung rasio-rasio keuangannya yang mencakup rasio leverage, aktivitas dan profitabilitas perusahaan. Pada kesempatan ini penelitian dilakukan pada PT. Asuransi Sinar Mas Tbk untuk menilai kinerja keuangan perusahaan dengan menggunakan Rasio Leverage dan rasio Profitabilitas pada laporan keuangan Perusahaan PT. Asuransi Sinar Mas Tbk periode 2011-2020. 
Tabel 1. Perkembangan Debt to Asset Ratio s (DAR) dan Return On Asset (ROA)PT. Asuransi Sinar Mas Tbk, Periode 2011-2020

\begin{tabular}{c|c|c} 
Tahun & Debt to Asset Ratio (DAR) $(\%)$ & Return On Asset (ROA) $(\%)$ \\
\hline 2011 & 65.44 & 5.89 \\
\hline 2,012 & 68 & 6 \\
\hline 2,013 & 77 & 3 \\
\hline 2,014 & 70 & 4 \\
\hline 2,015 & 67 & 5 \\
\hline 2,016 & 64 & 5 \\
\hline 2,017 & 62 & 5 \\
\hline 2,018 & 68 & 5 \\
\hline 2,019 & 69 & 5 \\
\hline 2,020 & 67 & 6 \\
\hline Rata-rata & 67.69 & 5.05 \\
\hline
\end{tabular}

Berdasarkan data pada tabel di atas, menunjukkan bahwa sepanjang tahun 20112020 pertumbuhan leverage secara keseluruhan Debt to Asset Ratio rata-rata mengalami perkembangan yang fluktuatif. Persentase pencapaian Debt to Asset Ratio tertinggi terjadi pada tahun 2013 yang mencapai sebesar 76,71\%, sedangkan persentase pencapaian terendah terjadi pada tahun 2017 yang hanya mencapai 62,31\%. Secara ratarata dicapai $67,69 \%$ per tahunnya.

Kondisi serupa juga terjadi pada persentase pencapaian Return On Asset yang perkembangannya dari tahun ke tahun mengalami hal yang serupa. Persentase Return On Asset tertinggi terjadi pada tahun 2012 yakni sebesar 6,34\% dan Return On Asset terendah terjadi pada tahun 2013 sebesar 2,55\%. Secara rata-rata dicapai 5,05\%.

Berdasarkan hasil tersebut, peneliti tertarik untuk menelusuri bagaimana kinerja perusahaan PT. Asuransi Sinar Mas Tbk Periode 2011-2020 yang selanjutnya ditetapkan untuk membuat judul skripsi "Analisis Pengaruh Debt to Asset Ratio Terhadap Return On Asset Pada PT. Asuransi Sinar Mas Tbk Periode 2011-2020”.

\section{B. Rumusan Masalah}

a. Bagaimana kondisi Debt to Asset Ratio pada PT. Asuransi Sinar Mas, Tbk ?.

b. Bagaimana kondisi Return On Asset pada PT. Asuransi Sinar Mas, Tbk ?.

c. Adakah pengaruh Debt to Asset Ratio terhadap Return On Asset pada PT. Asuransi Sinar Mas, Tbk?.

\section{Tujuan Penelitian}

a. Untuk mengetahui kondisi Debt to Asset Ratio pada PT. Asuransi Sinar Mas, Tbk.

b. Untuk mengetahui kondisi Return On Asset pada PT. Asuransi Sinar Mas, Tbk.

c. Untuk mengetahui pengaruh Debt to Asset Ratio terhadap Return On Asset pada PT. Asuransi Sinar Mas, Tbk.

\section{METODE PENELITIAN}

\section{Populasi}

Populasi dalam penelitian ini laporan keuangan PT. Asuransi Sinar Mas, Tbk selama 10 tahun

\section{Sampel}

Teknik pengambilan sampling dalam penelitian ini adalah samplel jenuh, dimana semua anggota populasi dijadikan sebagai sampel. Dengan demikian sampel dalam penelitian ini laporan keuangan PT. Asuransi Sinar Mas, Tbk selama 10 tahun. 


\section{Jenis Penelitian}

Jenis penelitian yang dipakai adalah kuantitatif, dimana tujuannya adalah untuk mengetahui mencari keterhubungan antara variabel independen terhadap variabel dependennya

\section{Metode Analisis Data}

Dalam menganalisis data digunakan analisis deskriptif, analisis regresi linier sederhana, koefisien korelasi, koefisien determinasi dan uji hipotesis.

\section{HASIL PENELITIAN}

\section{Analisis Deskriptif}

Pada pengujian ini digunakan untuk mengetahui skor minimum dan maksimum skor tertinggi, ratting score dan standar deviasi dari masing-masing variabel. Adapun hasilnya sebagai berikut:

Tabel 2. Hasil Analisis Descriptive Statistics

\section{Descriptive Statistics}

\begin{tabular}{lr|r|r|r|r} 
& N & \multicolumn{1}{c|}{ Minimum } & Maximum & \multicolumn{1}{c|}{ Mean } & Std. Deviation \\
\hline DAR & 10 & 62.31 & 76.71 & 67.6890 & 3.96214 \\
\hline ROA & 10 & 2.55 & 6.34 & 5.0480 & 1.07581 \\
\hline Valid N (listwise) & 10 & & & & \\
\hline
\end{tabular}

Debt to Asset Ratio diperoleh nilai minimum sebesar 62,31\% dan nilai maximum $76,71 \%$ dengan rata-rata sebesar $67,68 \%$ dengan standar deviasi 3,962\%. Sedangkan nilai Return On Asset diperoleh nilai minimum sebesar 2,55\% dan nilai maximum 6,34\% dengan rata-rata sebesar $1,075 \%$ dengan standar deviasi $1,129 \%$.

\section{Analisis Kuantitatif}

Pada analisis ini dimaksudkan untuk mengetahui pengaruh variabel independen terhadap variabel dependen. Adapun hasil pengujian sebagai berikut:

\section{a. Analisis Regresi Linier Sederhana}

Uji regresi ini dimaksudkan untuk mengetahui perubahan variabel dependen jika variabel independen mengalami perubahan. Adapun hasil pengujiannya sebagai berikut:

Tabel 3. Hasil Pengujian Regresi Linier Sederhana

\begin{tabular}{|c|c|c|c|c|c|c|}
\hline \multicolumn{7}{|c|}{ Coefficients } \\
\hline \multirow[b]{2}{*}{ Model } & & \multicolumn{2}{|c|}{$\begin{array}{l}\text { Unstandardized } \\
\text { Coefficients }\end{array}$} & \multirow{2}{*}{$\begin{array}{c}\text { Standardized } \\
\text { Coefficients } \\
\text { Beta }\end{array}$} & \multirow[b]{2}{*}{$\mathrm{t}$} & \multirow[b]{2}{*}{ Sig. } \\
\hline & & $\mathrm{B}$ & Std. Error & & & \\
\hline 1 & (Constant) & 17.889 & 4.656 & & 3.842 & .005 \\
\hline & DAR & -.190 & .069 & -.699 & -2.762 & .025 \\
\hline
\end{tabular}

a. Dependent Variable: ROA

Berdasarkan hasil pengujian pada tabel di atas, diperoleh persamaan regresi Y $=17,889-0,190 X$. Dari persamaan tersebut dijelaskan sebagai berikut:

1) Konstanta sebesar 17,889 diartikan jika Debt to Asset Ratio tidak ada, maka telah terdapat nilai Return On Asset sebesar 17,889 point.

2) Koefisien regresi Debt to Asset Ratio sebesar --0,190, angka ini negatif artinya setiap ada peningkatan Debt to Asset Ratio sebesar --0,190 point maka Return On Asset juga akan mengalami perubahan sebesar --0,190 point.

\section{b. Analisis Koefisien Korelasi}

Analisis koefisien korelasi dimaksudkan untuk mengetahui tingkat kekuatan hubungan dari variabel independen terhadap variabel dependen. Adapun hasil 
pengujian sebagai berikut:

Tabel 4. Hasil Pengujian Koefisien Korelasi Debt to Asset Ratio Terhadap Return On Asset.

\begin{tabular}{llrr}
\multicolumn{3}{c}{$\begin{array}{c}\text { On Asset. } \\
\text { Correlations }\end{array}$} \\
\multicolumn{1}{c}{ DAR } & \multicolumn{2}{c}{ ROA } \\
\hline DAR & Pearson Correlation & 1 & $-.699^{*}$ \\
\cline { 2 - 4 } & Sig. (2-tailed) & .025 & .025 \\
\hline ROA & Pearson Correlation & $-.699^{*}$ & 1 \\
\cline { 2 - 4 } & Sig. (2-tailed) & .025 & \\
\hline *. Correlation is significant at the 0.05 level (2-tailed). & \\
b. Listwise N=10 &
\end{tabular}

Berdasarkan hasil pengujian pada tabel di atas diperoleh nilai korelasi sebesar -0,699 artinya Debt to Asset Ratio memiliki hubungan yang negatif kuat terhadap Return On Asset.

\section{c. Analisis Koefisien Determinasi}

Analisis koefisien determinasi dimaksudkan untuk mengetahui besarnya persentase pengaruh dari variabel independen terhadap variabel dependen. Adapun hasil pengujian sebagai berikut:

Tabel 5. Hasil Pengujian Koefisien Determinasi Debt to Asset Ratio Terhadap

\section{Return On Asset.}

Model Summary

\begin{tabular}{lr|r|r|r} 
Model & $\mathrm{R}$ & $\mathrm{R}$ Square & Adjusted R Square & Std. Error of the Estimate \\
\hline 1 & $.699^{\mathrm{a}}$ & .488 & .424 & .81639 \\
\hline a. Predictors: (Constant), DAR &
\end{tabular}

Berdasarkan hasil pengujian pada tabel di atas diperoleh nilai determinasi sebesar 0,488 artinya Debt to Asset Ratio memiliki kontribusi pengaruh sebesar 48,8\% terhadap Return On Asset, sedangkan sisanya sebesar 51,2\% dipengaruhi faktor lain.

\section{d. Uji Hipotesis}

Pengujian hipotesis dengan uji t digunakan untuk mengetahui hipotesis mana yang diterima. Rumusan hipotesis: Terdapat pengaruh yang signifikan Debt to Asset Ratio terhadap Return On Asset.

Tabel 6. Hasil Uji Hipotesis Debt to Asset Ratio Terhadap Return On Asset.

\begin{tabular}{|c|c|c|c|c|c|c|}
\hline & & & Coefficients & & & \\
\hline & & $\begin{array}{r}\text { Unstan } \\
\text { Coef }\end{array}$ & $\begin{array}{l}\text { ardized } \\
\text { cients }\end{array}$ & $\begin{array}{l}\text { Standardized } \\
\text { Coefficients }\end{array}$ & & \\
\hline & & B & Std. Error & Beta & $\mathrm{t}$ & Sig. \\
\hline 1 & (Constant) & 17.889 & 4.656 & & 3.842 & .005 \\
\hline & DAR & -.190 & .069 & -.699 & -2.762 & .025 \\
\hline
\end{tabular}

Berdasarkan hasil pengujian pada tabel di atas, diperoleh nilai signifikansi < 0,05 atau $(0,025<0,05)$, dengan demikian terdapat pengaruh yang signifikan antara Debt to Asset Ratio terhadap Return On Asset.

\section{Pembahasan Hasil Penelitian}

\section{Kondisi Nilai Variabel Debt to Asset Ratio}

Berdasarkan data empiris pada tabel di atas dan analisis data, variabel Debt to Asset Ratio dari data laporan keuangan selama 10 tahun diperoleh nilai rata-rata per tahun sebesar 67,68\%. 


\section{Kondisi Nilai Variabel Return On Asset}

Berdasarkan data empiris pada tabel di atas dan analisis data, variabel Return On Asset dari data laporan keuangan selama 10 tahun diperoleh nilai rata-rata per tahun sebesar $1,075 \%$.

\section{Pengaruh Debt to Asset Ratio Terhadap Return On Asset}

Debt to Asset Ratio berpengaruh signifikan terhadap Return On Asset dengan persamaan regresi $\mathrm{Y}=17,889--0,190 \mathrm{X}$, nilai korelasi sebesar $-0,699$ atau memiliki hubungan yang kuat dengan kontribusi pengaruh sebesar $48,8 \%$, sedangkan sisanya sebesar 51,2\% dipengaruhi oleh faktor lain yang tidak dilakukan penelitian. Pengujian hipotesis diperoleh nilai signifikansi $<0,05$ atau $(0,025<0,05)$. Dengan demikian terdapat pengaruh yang signifikan antara Debt to Asset Ratio terhadap Return On Asset.

\section{KESIMPULAN DAN SARAN}

\section{Kesimpulan}

a. Kondisi variabel Debt to Asset Ratio berdasar pada periode laporan keuangan 10 tahun diperoleh Debt to Asset Ratio rata-rata sebesar 67,68\%.

b. Kondisi variabel Return On Asset berdasar pada periode laporan keuangan 10 tahun diperoleh Debt to Asset Ratio rata-rata sebesar 1,075\%.

c. Debt to Asset Ratio berpengaruh signifikan terhadap Return On Asset dengan persamaan regresi $\mathrm{Y}=17,889$ - 0,190X, nilai korelasi sebesar -0,699 atau kuat dan kontribusi pengaruh sebesar 48,8\% sedangkan sisanya sebesar $51,2 \%$ dipengaruhi faktor lain. Uji hipotesis diperoleh nilai signifikansi $<0,05$ atau $(0,025<0,05)$. Dengan demikian terdapat pengaruh yang signifikan antara Debt to Asset Ratio terhadap Return On Asset.

\section{Saran}

Berdasarkan hasil penelitian yang sudah disimpulkan, maka penulis memberikan saran sebagai berikut:

a. Melihat kondisi solvabilitas perusahaan selama periode 2011-2020 masih fluktuatif menurun. Maka perusahaan perlu berusaha meningkatkan jumlah modal dan aktiva sehingga perusahaan dapat memenuhi kewajibannya dengan baik.

b. Bagi peneliti selanjutnya disarankan untuk melakukan penelitian di luar variabel independen yang digunakan dalam penelitian ini ataupun mengkombinasikan salah satu vaiabel dalam penelitian ini dengan vaiabel lain diluar variabel dalam penelitian ini, agar dapat memperoleh hasil yang lebih bervariatif yang dapat menggambarkan hal-hal apa saja yang dapat berpengaruh terhadap Return on Assets

\section{DAFTAR PUSTAKA}

Agus Harjito \& Martono, (2015) "Manajemen Keuangan" Yogyakarta: Penerbit Ekonisia. Agus Sartono. (2016). "Manajemen Keuangan Toeri dan Aplikasi”, Edisi keempat, Yogyakarta: Penerbit BPFE.

Algifari. (2015). “Analisis Regresi untuk Bisnis dan Ekonomi”. Yogyakarta: BPFE.

Arikunto, Suharsimi (2014). "Prosedur Penelitian Suatu Pendekatan Praktek". Jakarta: Rineka Cipta.

Bambang Riyanto, (2011). "Dasar-dasar Pembelanjaan Perusahaan". Edisi ke empat, Yogyakarta: BPFE. 
Dumilah, R. et al (2021). Pengaruh Likuiditas Dan Profitabilitas Terhadap Struktur Modal Pada PT Mayora Indah, Tbk Periode 2010-2019. Jurnal Neraca Peradaban. 1(3) 237245

Fahmi, Irham (2012), "Pengantar Manajemen Keuangan" Cetakan pertama. Bandung: Penerbit Alfabeta.

Hanadelansa, H., et al. (2019). Analisis Audit Operasional Atas Pemberian Kredit Pemilikan Rumah Pada PT Bank Rakyat Indonesia (Persero) Tbk Kantor Cabang Panakukkang Di Kota Makassar. SENTRALISASI, 8(1), 33-42.

Imam Ghozali (2017). "Aplikasi Analisis Multivariate Dengan Program SPSS". Edisi Kelima. Semarang: Badan Penerbit Undip.

Istijanto (2014) "Riset Sumber Daya Manusia". Jakarta: PT. Gramedia Pustaka

Kasmir. (2012) "Pengantar Manajemen Keuangan”, Edisi Pertama, Cetakan kedua, Jakarta: Prenada Media.

Martono dan Agus Harjito, (2011). "Manajemen Keuangan”, Jakarta: Penerbit Ekonisia.

Munawir (2010), “Analisis Laporan Keuangan”, Edisi Ke Empat, Yogyakarta: Penerbit Liberty.

Pangaribuan, H., et al. (2021). The Financial Perspective Study on Tax Avoidance. Budapest International Research and Critics Institute (BIRCI-Journal): Humanities and Social Sciences, 4(3), 4998-5009.

Santoso, Singgih (2015). "Menguasai Statistik Multivariat". Jakarta: PT Elex Media Komputindo.

Sartono, "Manajemen Keuangan Aplikasi Dan Teori", Edisi Keempat, BPFE, Yogyakarta, 2008.

Sawir, (2003). "Analisis Kinerja Keuangan dan Perencanaan Keuangan Perusahaan", Cetakan ketiga, Jakarta: Penerbit PT. Gramedia Pustaka Utama.

Sugiyarso, G. dan F. Winarni, "Manajemen Keuangan (Pemahaman Laporan Keuangan, Pengelolaan Aktiva, Kewajiban dan Modal serta Pengukuran

Sugiyono (2017), "Metode Penelitian Administrasi : dilengkapi dengan Metode R \& D". Bandung: Alfabeta. 